\title{
JOVENS MULHERES DE PERIFERIA E O FUNK OSTENTAÇÃO
}

\author{
Karla Saraiva \\ JuLIANA VARGAS \\ Universidade Luterana do Brasil (ULBRA), \\ Canoas, Rio Grande do Sul, Brasil
}

\begin{abstract}
Resumo: O artigo visa analisar relações estabelecidas entre jovens alunas de uma escola da periferia do município de Porto Alegre (RS) e o estilo musical funk ostentação. Mais especificamente, busca-se problematizar a construção de ideais de relacionamentos afetivo-sexuais e de relações de gênero, pelas jovens, em articulação com tais músicas. Primeiramente, analisam-se as cinco músicas de maior evidência entre as jovens e, posteriormente, problematizam-se os dados produzidos em grupos de discussão. Dentre os resultados, destacamos a acolhida das jovens para os enunciados que destacam os homens como promotores financeiros dos sonhos de consumo femininos e seus anseios por relacionamentos de maior durabilidade, contrariando a representação de sucessivos relacionamentos breves apresentados nas suas músicas preferidas.

Palavras-chave: Estudos Culturais. Gênero. Consumo. Música.
\end{abstract}

O morro não tem vez

E o que ele fez já foi demais

Mas olhem bem vocês

Quando derem vez ao morro

Toda a cidade vai cantar

Tom Jobim e Vinicius de Moraes ${ }^{1}$ 
É possível pensar que os versos da música destacados na epígrafe ilustrem a incorporação de muitas das produções realizadas no espaço da periferia pela população dos centros urbanos brasileiros. Se nos tempos em que foi composta, a música de Tom Jobim e Vinicius de Moraes retratava, de modo específico, as músicas relacionadas ao samba e ao carnaval da cidade do Rio de Janeiro produzidas nos morros da cidade, pode-se pensar que hoje, tais versos possam também ser relacionados ao movimento de incorporação de produções musicais de outros ritmos realizadas no espaço da periferia. Nos tempos atuais, não somente o samba, mas as produções do funk seguem "descendo o morro" e são apreciadas e consumidas pelos ditos sujeitos do asfalto, residentes em bairros nobres das cidades de nosso país. $\mathrm{E}$, mesmo sem conhecer ou admirar, de um modo geral, quase toda a cidade acaba por cantar músicas compostas por artistas populares, principalmente quando essas "estouram" nas rádios, na web ou ainda, quando constituem a trilha sonora de alguma novela televisiva.

Compreendemos o samba, o funk, assim como outros gêneros musicais presentes na cultura brasileira, como constituindo dimensões educativas, que ensinam modos de ser e de conviver, tanto para aqueles que vivenciam diretamente sua produção, a exemplo dos músicos, ritmistas e Mcs, como também para os ouvintes e apreciadores dos diferentes gêneros musicais. Desta forma, apropriando-nos do conceito de pedagogia cultural, entendido como sendo um rol de práticas "culturais extraescolares que participam de" forma incisiva na constituição de sujeitos (COSTA, 2010, p. 137), exploramos neste artigo uma possível dimensão pedagógica do gênero funk na constituição de feminilidades em grupo de jovens estudantes, moradoras de uma comunidade de periferia de Porto Alegre (RS). Mais precisamente, o objetivo deste artigo é problematizar a relação de um grupo de 14 jovens mulheres com o funk ostentação, a fim de mostrar os possíveis efeitos deste gênero musical na construção de suas identidades de gênero e de um ideal de relacionamento sexual-afetivo. As análises apresentadas neste artigo foram realizadas a partir de uma pesquisa desenvolvida com alunas do último ano do Ensino Fundamental em uma escola de periferia no município de Porto Alegre, no sul do Brasil.

Os campos teóricos dos Estudos Culturais e dos Estudos de Gênero, em vertente pós-estruturalista e também as teorizações de Lazzaratto, selecionados para subsidiar este estudo, permitem o aprofundamento da temática de análise. Em consonância com tais campos, compreendemos os sujeitos como constituídos por práticas, segundo as condições de possibilidades de 
distintos contextos históricos e sociais. Logo, as jovens pesquisadas estariam sendo subjetivadas de distintos modos em suas possibilidades de vida e, desta forma, constituiriam suas feminilidades frente aos diferentes discursos que as atravessam, bem como suas concepções acerca de relacionamentos afetivo-sexuais. Ainda, a partir da perspectiva dos Estudos Culturais, é possível assumir as músicas escutadas pelas alunas como produções culturais que promovem ações comunicativas/identitárias junto aos grupos sociais nos quais as jovens alunas transitam.

Vale destacar que assim como o samba, o funk principia suas produções no cenário brasileiro em meio às comunidades de periferia urbana das grandes cidades, como mostramos na próxima seção. A seguir, apresentamos os percursos metodológicos da pesquisa e, posteriormente, analisamos as músicas e o material empírico oriundo dos grupos de discussão realizados com as jovens, focando neste trabalho o subgênero conhecido como funk ostentação. Encerramos este estudo com a certeza de que outras possibilidades de análise poderiam ter sido exploradas, frente ao material empírico constituído, na procura de visibilidade para dimensões ainda pouco estudadas no que se refere à constituição da juventude feminina e de seus ideais acerca de relacionamentos afetivo-sexuais.

\section{RITMOS QUE DESCERAM O MORRO}

Os morros e favelas do Rio de Janeiro, bem como, em menor medida, as periferias de outras cidades brasileiras, tiveram, desde o final do século XIX, uma forte relação com o samba. Este gênero musical aglutinava comunidades em torno de atividades diversificadas, como bailes e rodas de samba. Pouco a pouco, foram aparecendo os blocos carnavalescos e, por fim, as escolas de samba. Ao final dos anos 1920, se percebe uma definição paradigmática do samba, conjuntamente com a organização das primeiras escolas de samba no Rio de Janeiro (LIMA, 2002). De acordo com Cabral (1996), o primeiro desfile de escolas de samba deu-se em 1932, no Rio de Janeiro. A partir de então, o samba difunde-se pelo Brasil, sendo tramado fortemente com a constituição da identidade nacional. Apesar de estar associado com as classes populares e com a cultura negra, gradativamente foi sendo aceito pelas classes mais favorecidas e pelos brancos. A escola de samba tornou-se uma instituição de grande importância nas periferias brasileiras, recebendo, em muitos casos, a participação de sujeitos de fora da comunidade. 
Já o funk aporta no Brasil nos anos 1970, originário assim como o rap, da música negra norte-americana, a qual incorporou sonoridades africanas, baseadas no ritmo e na tradição oral (DAYRELL, 2002). É importante pontuar também que o termo funk ou funky surge associado à ideia de "orgulho negro", como destaca Hermano Vianna (1987, p.45):"Em 68, o soul já tinha se transformado em um termo vago, sinônimo de 'black music', [...] Foi nessa época que a gíria funky [...] deixou de ter um significado pejorativo, quase um palavrão, e começou a ser um símbolo do orgulho negro". Este gênero musical, ao aportar no Brasil, sofre transformações, resultando em uma produção nacional com características próprias, em especial no Rio de Janeiro, diferindo do gênero norte-americano e marcando a emergência do que passou a ser conhecido como funk carioca. $\mathrm{O}$ desnecessário domínio de habilidades técnicas musicais e a organização de eventos a baixo custo para divulgação dos artistas são fatores que colaboraram para a proliferação de grupos de rap e funk nas periferias urbanas brasileiras (DAYRELL, 2001).

Ao final dos anos de 1980, as produções nacionais relacionadas ao funk se fortalecem, constituindo, como denomina Dayrell (2001), o processo de nacionalização do funk que se evidencia, primeiramente, pela introdução de letras em português sobre a base de acordes estrangeiros para a produção de músicas (PLATT; NEATE, 2008). De acordo com Coelho (2004), este novo gênero musical surge em meio às disparidades econômicas e ao aumento da violência ligada ao tráfico de drogas, promovendo um aumento de desconfiança entre os diferentes extratos sociais. Se o samba, surgido nas periferias, parece ter tido uma vocação integradora, não promovendo conflitos de classe, o funk carioca se notabiliza, em um primeiro momento, pelas suas letras agressivas, fazendo frequentemente apologia ao crime e à violência ou com forte conteúdo erótico. Destaca ainda Herschmann (2005) que discursos jornalísticos produzidos na década de 1990 descrevem a juventude "perigosa" das periferias urbanas como os participantes dos bailes funk em razão dos episódios de violência ocorridos nestes ambientes. De acordo com o autor (HERSCHMANN, 2005, p.101) "[...] o estigma do funk não se dirige exatamente contra o baile (apesar de ele ser o objeto central do debate entre o Estado, sociedade e órgãos de segurança), mas contra o setor social que os assumiu como forte referencial identitário", qual seja, os moradores das periferias urbanas.

Este novo gênero musical passou a ocupar cada vez mais o espaço do samba, não apenas em termos figurado, como também físico: muitos bailes funk acontecem nas quadras das escolas de samba. Desde o início da 
década de 1990, assiste-se um deslizamento nas comunidades de periferia de uma cultura calcada no samba para a cultura do funk. Com isto, não estamos dizendo que o samba desapareceu, mas que foi ressignificado e perdeu parte de sua importância, principalmente entre os jovens dessas comunidades de periferia. Em um novo deslocamento, no final dos anos 2010, surge em São Paulo o que hoje é chamado de funk ostentação, uma variação do funk carioca caracterizada por letras que exaltam a ostentação de símbolos de consumo, como carros e motos de luxo, roupas e tênis "de marca" e gastos exorbitantes e extravagantes em festas e casas noturnas. Muito escutado por jovens, principalmente nas periferias de grandes cidades, embalando sonhos de consumo e de uma vida de fausto, o funk ostentação tem sua origem ligada à emergência de uma nova classe média no Brasil a partir de um cenário político-econômico que promoveu a ascensão social de segmentos mais pobres da população, permitindo que entrassem para um mundo de consumo inédito. É possível perceber que, na atualidade, muitos moradores das regiões de periferia urbana brasileira têm investido em bens de alto valor, como celulares, smartphones, televisores de tela plana e computadores. Percebe-se que os recém-chegados à classe $C$ passam a desejar os produtos de luxo, fazendo, em muitas situações, grandes sacrifícios para comprá-los.

Na etapa da pesquisa em que foram analisadas as músicas presentes nos cartões de memória das jovens alunas, constatamos que o funk ostentação foi o subgênero musical que contou com o maior número de composições, denotando sua importância para o grupo. Na seção seguinte, detalhamos o percurso desenvolvido no processo investigativo que sustenta este artigo.

\section{OS CAMINHOS METODOLÓGICOS}

As 14 jovens mulheres que foram sujeitos desta pesquisa escutavam e compartilhavam suas músicas preferidas através dos aparelhos celulares, inclusive em diversos momentos da rotina escolar. Muitas vezes, o faziam em meio às atividades de sala de aula, não acatando o regulamento vigente na rede de ensino que proíbe o uso de tais aparatos no ambiente letivo. Para desenvolver o presente estudo, em um primeiro momento dispusemo-nos a conhecer os arquivos musicais armazenados pelas jovens nos cartões de memória acoplados a seus aparelhos celulares em três períodos distintos, entre os anos de 2012 e 2013, listando todos os arquivos musicais que cada uma delas armazenava. Com isto, foi possível inferir que a maioria das estu- 
dantes possuía mais de uma centena de músicas diferentes em seus cartões. A primeira etapa do levantamento das músicas foi realizada em julho de 2012, a segunda, em novembro de 2012, e a terceira em abril de 2013. Foram selecionadas 114 músicas, sendo o critério para a seleção o fato de aparecerem de forma recorrente nos cartões de memórias das jovens pesquisadas. Os gêneros musicais mais apreciados pelas referidas alunas permaneceram os mesmos em todos os momentos pesquisados, com forte predominância do funk, em especial o funk ostentação, seguido pelo pagode e pelo sertanejo.

Nesta pesquisa, tomamos os aparelhos celulares como diários digitais contemporâneos, uma vez que se prestam à comunicação e ao registro de imagens e músicas, que podem permanecer armazenadas nos cartões de memória do equipamento. No entanto, é importante pontuar a provisoriedade e a flexibilidade que tal recurso comporta, uma vez que cada usuário pode apagar e/ou registrar "novas memórias" com muita rapidez, reconfigurando continuamente este diário. Inclusive, o diário pode mudar de dono e fazer com que as memórias do antigo e do novo proprietário se mesclem, como é possível visualizar na narrativa de Ingrid, uma das participantes do estudo:

[...] o meu cartão de memória não quer mais entrar no meu celular. Aí eu peguei o cartão de memória do meu irmão [...] agora, vou apagar as músicas que estão aqui [no cartão] e eu não gosto.

De posse dos dados produzidos a partir do levantamento dos arquivos musicais dos cartões de memória, estabelecemos estratégias de análise das músicas que apareceram com maior frequência no grupo. Tais análises foram balizadoras para a organização dos grupos de discussão, metodologia que nos permitiu compreender melhor como as músicas operavam na constituição das subjetividades, das identidades e das representações das alunas. Foi a partir dos grupos de discussão que se tornou mais claro para nós o modo como as jovens estabeleciam relações do funk ostentação com as suas vivências de gênero e com o modo como compreendiam e idealizavam os relacionamentos de cunho afetivo-sexual.

Compartilhamos com Meinerz (2011, p. 486) o entendimento de que a metodologia do grupo de discussão abre a possibilidade de escuta sensível, que não se fundamenta apenas em rigores teóricos para sua realização, uma vez que tal escuta é dependente da postura "política, afetiva e ética do pesquisador". Para melhor organização da referida metodologia, as 14 alunas participantes foram divididas em quatro grupos, respeitando suas afinidades musicais. Buscamos destacar, nas seções seguintes, as preferências musicais 
elencadas pelas jovens pesquisadas relacionadas com o subgênero funk ostentação e problematizar a operacionalidade de determinados discursos na constituição dos ideais acerca dos relacionamentos sexual-afetivos que vivenciavam ou que pretendiam vivenciar.

FUNK OSTENTAÇÃO: O CONSUMO COMO PRÁTICA DE EXISTÊNCIA

Conforme já pontuamos, durante a pesquisa, entre as músicas que as jovens escutavam, aquelas associadas ao subgênero funk ostentação foram destaque. Vale destacar que a forte presença do funk na sociedade brasileira, em especial do subgênero conhecido como funk ostentação, pode ser percebida nas trilhas sonoras de novelas de grande audiência, na presença de artistas que produzem e cantam este tipo de música em programas de televisão e também pelos numerosos shows que os mesmos realizam mensalmente. De um modo geral, tal ritmo musical é associado às classes sociais de menor poder aquisitivo e, por conseguinte, supostamente com menor possibilidade de obtenção de bens de consumo. Apesar de sua produção ser recente, sendo seu surgimento observado em 2009, o funk ostentação já foi tema de documentários e de reportagens especiais de jornais e revistas de grande circulação e suas músicas traçam, em sua maioria, narrativas acerca dos "benefícios" que o acúmulo de bens e de patrimônio proporciona aos homens e mulheres jovens: a companhia de parceiros do sexo oposto e a elevação de um status frente aos demais².

Embora, na visão de seus intérpretes, tais músicas retratem possibilidades de vida a serem alcançadas pela população de periferia, é válido problematizar de que modo tais possibilidades são efetivadas frente às condições de vida que possuem os habitantes dessas regiões na atualidade. Apesar da ascensão econômica vivenciada por muitos desses habitantes, a aquisição de bens como carros e motos de luxo é impensável para a maioria da população.

Para realizar as análises que apresentamos nesta seção, selecionamos as cinco músicas do subgênero funk ostentação com maior recorrência nos celulares das participantes. São elas: Vem pode chamar que ela vem, de Mc Nego Blue; Eu sou patrão não funcionário, de Menor do Chapa; Rolê de Hayabusa, de Mc Dedé; Ela monta na minha R1, de Mc Bo do Catarina e Mulher do poder, de Mc Pocahontas. ${ }^{3}$ Para analisá-las, recortamos os enunciados referentes às construções de gênero em sua inter-relação com o consumo, 
bem como àqueles referentes ao tipo de relação que se pretende estabelecer com possíveis parceiros, articulando-os com os anteriores.

Destacamos que a maioria dessas músicas é cantada e composta por homens. Elas apresentam como protagonista um sujeito heterossexual, que exibe sinais de riqueza, principalmente em programas noturnos. É um sujeito que, ao falar de automóveis, afirma que "tá de Audi, Veloster, tá de Megane" (Menor do Chapa, Eu sou patrão não funcionário). Se for motocicleta, pode ser uma Hayabusa (Mc Dedé, Rolê de Hayabusa) ou uma R1 (Mc Bó do Catarina, Ela monta na minha R1). Ou seja, é um homem que se empodera não apenas por possuir um veículo automotor, como, além disto, de possuir um veículo de luxo.

Quanto às roupas, ele vai "de Lacoste e de Dolce Gabbana" (Mc Nego Blue, Vem pode chamar que ela vem), "da Ed Hardy, Rio Local ou da Armani" (Menor do Chapa, Eu sou patrão não funcionário) ou "Hollister e Abercrombie Fitch" (Mc Dedé, Rolê de Hayabusa). No pé, usa um tênis Puma Disk e o seu perfume é One Million (Mc Bo do Catarina, Ela monta na minha R1). Portanto, o protagonista destas músicas exibe sobre o corpo signos de consumo e de desejo dos jovens em geral, mas que só podem ser realizados por aqueles que contam com alto poder aquisitivo. Na balada, é uma espécie de rei. Pede "whisky com Red Bull e pra ela, Absolut no gelo" (Mc Bo do Catarina, Ela monta na minha R1). Fica na "área VIP, [...] no camarote". Esses são alguns dos elementos que remetem a um mundo de luxo e ostentação que aparecem nas músicas, mostrando a representação de riqueza que este subgênero musical assume.

Os carros, as motocicletas, as roupas, os acessórios, as bebidas e os serviços descritos nas músicas do funk ostentação são sofisticados e bastante caros. Os compositores, oriundos em sua maioria de regiões de periferia urbana, referem-se em suas letras a bens reservados, de modo geral, àqueles com poder aquisitivo elevado. Eles, possivelmente, apenas conseguiram ou conseguirão utilizá-los após alcançar algum sucesso por meio da visibilidade e popularidade de suas músicas. Cabe notar que, se nos tempos antes da internet, o sucesso musical expressava-se pela venda de discos, atualmente, está relacionado principalmente com visualizações e curtidas que os vídeos das músicas recebem nas plataformas digitais, sendo o Youtube o exemplo mais representativo destas ferramentas. Quanto maior o número de acessos que os vídeos de um artista apresentam, mais extensa (e rentável) torna-se sua agenda de shows. Desta forma, é por meio dos vídeos disponibilizados gratuitamente na internet, mesmo antes de gravarem algum $C D$, que os músicos ligados ao funk ostentação (bem como a outros gêneros populares entre 
os jovens) obtém o reconhecimento de fãs e fazem sucesso, conseguindo assim uma alta renda.

De acordo com Lazzarato (2006, p.100), "consumir não se reduz mais a comprar e a'destruir' um serviço ou um produto [...], mas significa, sobretudo, pertencer a um mundo, aderir a um universo". Para este autor, as empresas não criam, em um primeiro momento, mercadorias, mas mundos onde os objetos existem e onde o consumo é efetuado nas almas dos consumidores. As grandes marcas consistem em empresas potentes, com competentes profissionais de marketing para construção e disseminação de seus mundos pelos cérebros. Esses mundos se capilarizam e atuam a distância sobre grandes multiplicidades, criando públicos densos e numerosos.

Neste sentido, pode-se dizer que na contemporaneidade coexistem infinitos mundos, que criam infinitos públicos. Ou seja, antes de comprarmos algo, devemos pertencer a seu mundo. A partir desta perspectiva, Lazzarato (2006) afirma ainda que todos consomem os mesmos produtos virtualmente, porém este consumo se efetua apenas em alguns corpos, naqueles que possuem recursos para sua aquisição. Portanto, mesmo que as jovens investigadas neste estudo não possuam os objetos que constam nas letras de suas músicas preferidas, elas pertencem a esses mundos e os consomem virtualmente. E é por esta razão que estas marcas se fazem presente nas letras do funk ostentação: elas funcionam como um atrativo para o público, reforçando a pertença a estes mundos do consumo.

Assim, entendemos que as jovens, de modo semelhante aos músicos, pertencem aos mundos Audi, R1, Armani ou Puma e anseiam em materializar o consumo em seus corpos. Lazzarato (2006) ainda nos auxilia na compreensão das práticas de subjetivação em funcionamento nas sociedades de controle, destacando a potência dos dispositivos tecnológicos e midiáticos para a articulação de tais práticas. Desta forma, podemos pensar que determinados dispositivos tecnológicos/midiáticos, a exemplo de sites como o Youtube, nos quais os vídeos das músicas de funk ostentação podem ser visualizados, operem como instrumentos das práticas de subjetivação na sociedade atual, que entendemos ser, na esteira de Deleuze (1992), sociedades de controle. ${ }^{4}$ Músicas como as analisadas neste estudo parecem disponibilizar "especialmente a jovens e crianças, um novo repertório de valores e de comportamentos, muitas vezes conflitantes com aqueles que são apresentados nos ambientes escolares", tal como afirmam Saraiva e Veiga-Neto (2009, p. 197), ou ainda, em desconexão com as condições socioeconômicas de maior parte da população brasileira. 
É preciso destacar que a exibição dos sinais de riqueza pelos cantores nas músicas de funk ostentação parece ter por objetivo principal atrair não somente o maior número de mulheres, como também as mais desejáveis. Mc Dedé, autor da música Rolê de Hayabusa, corrobora esta afirmação ao cantar "meninas solteiras o baile é de vocês; vem dançando uma de cada vez". Por sua vez, Mc Menor do Chapa, no funk Eu sou patrão não funcionário, proclama: "só pego as melhores". Ou seja, esses homens parecem não querer conquistar uma única e determinada mulher, mas em suas canções evidenciam o anseio de múltiplos relacionamentos breves e de cunho sexual. $\mathrm{O}$ amor romântico, tão presente até hoje nos mais variados gêneros musicais, parece ter sido apagado no funk ostentação. A intenção de conquistar mulheres com objetivos sexuais fica clara quando Mc Bó do Catarina, na música Ela monta na minha R1, afirma que "um cinco estrelas ela adora". Neste excerto, percebemos, também, que o autor entende que as conquistas se baseiam, principalmente, não na atração pela beleza física, mas no luxo que ele pode proporcionar a sua parceira. No mesmo sentido, Mc Nego Blue, na sua composição Vem pode chamar que ela vem, declara:"não se preocupa com a grana; porque o pitstop da noite vai ser na minha cama".

Expressões como"Estilo panicat, me deu mole quando viu"(Mc Menor do Chapa, Eu sou patrão não funcionário) e "cheia de tesão" (Mc Bo do Catarina, Ela monta na minha R1) parecem evidenciar o suposto interesse feminino sobre as figuras masculinas que detêm os bens destacados nas músicas: um automóvel Audi, uma motocicleta R1 ou, simplesmente, um tênis da marca Puma Disk. O dinheiro e o acúmulo de bens de alto valor de consumo podem garantir a um homem, segundo a letra da música Pode chamar que ela vem (Mc Nego Blue), a possibilidade de relacionamentos simultâneos com duas mulheres: a fiel e a amante. Segundo o autor, "conta várias de cem, fazendo elas gama".

Durante a produção dos dados da pesquisa, apenas uma única música no gênero funk ostentação, cantada e composta por uma mulher, recebeu destaque. A música tem por título Mulher do poder e foi composta pela Mc Pocahontas. Esta música também apresenta signos do consumo análogos àqueles que aparecem nas músicas compostas por homens, sinalizando um desejo por motocicletas Hornet ou R1, automóveis Camaro, roupas e acessórios de luxo. Ela afirma desejar uma bolsa Louis Vuitton, acessório feminino de alto valor. $O$ modo como ela entende que terá acesso a esses bens é complementar àquele aludido pelos cantores nas músicas anteriormente referidas. Ela diz que "se me quer do seu lado, tem que me fazer rir [...] me 
dá condição". Ou seja, ela não conquistaria estes bens por meio de renda própria, como seria o caso dos compositores masculinos, mas pela conquista de homens que possam suprir a efetuação de seu consumo. Aqui, também, o amor romântico não tem vez. Se eles desejam as melhores mulheres e estão dispostos a utilizar seus recursos para tanto, Mc Pocahontas mostra o outro lado da moeda: pretende tirar vantagens materiais de sua beleza, estando disponível para relacionamentos somente com aqueles capazes de the oferecer os produtos e os serviços de luxo que deseja.

Deste modo, consideramos ser possível afirmar que as letras do subgênero funk ostentação, analisadas neste estudo, reforçam uma concepção de que homens devem prover recursos materiais, enquanto mulheres devem usufruir destes recursos por meio de relacionamentos mantidos com base em uma troca interessada. As letras compostas por homens mostram uma masculinidade extremamente sexualizada e com uma ânsia de dominação de múltiplas mulheres, o que seria viabilizado pela ostentação de produtos que os tornam admirados e poderosos. Por outro lado, a letra da Mc Pocahontas mostra uma mulher que, utilizando sua beleza, consegue fazer com que os homens supram seus sonhos mais extravagantes. Ela também acredita que os homens com quem se relaciona devem subsidiar seu consumo, porém não se reconhece como sendo dominada, mas antes como dominadora que consegue do parceiro vantagens financeiras. A partir de tais premissas, as músicas analisadas sugerem um ideal de relacionamento, para homens e mulheres, com pouco envolvimento afetivo, alta carga de sexualidade e, em geral, de curta duração. Porém, em relação à dominação, existem divergências, sendo que os homens consideram-se os dominadores, enquanto Mc Pocahontas declara o contrário.

Na próxima seção, analisamos os dados produzidos nos grupos de discussão cujo foco era a relação das meninas com o funk ostentação. Nosso objetivo é verificar como elas, ouvintes frequentes deste subgênero musical, negociam significados acerca de gênero e de relacionamentos a partir dessas músicas.

SE o CARA TEM DINHEIRO, ELE TEM QUE "BANCAR"- o QUe DIZEM AS JOVENS

Como destacamos na seção anterior, em muitas das músicas do funk ostentação, o provimento de bens materiais é apresentado, unicamente, como uma prática masculina oferecida às mulheres. As narrativas de algumas alunas participantes da pesquisa mostram que elas acolhem este tipo de representação. 
Paula: É legal porque mostra o poder da mulher!

Pesquisadora: Que tipo de poder a música mostra?

Cintia: Ela tem dinheiro, roupas, dinheiro...

Sophia: Ela tem o poder da... ${ }^{5} \mathrm{Tu}$ achas que ele deu dinheiro para ela por quê? Só porque ela deu beijinho nele?

Pesquisadora: Então por que ela "dá" para o cara e assim ganha tudo dele?

Paula: Não é porque ela dá, é porque ela merece! Se ele pega ela, ele tem quem ostentar!

Pesquisadora: Por que tu achas isso?

Sophia: Porque se o cara tem dinheiro ele tem que dar para ti!

Logo, as narrativas destacadas estariam filiadas a enunciados ainda amplamente aceitos por alguns segmentos da sociedade, tais como "o homem é quem paga!" ou "mulher deve ser sustentada por homem", os quais reverberam discursos sobre as diferenciações de possibilidades de vida entre homens e mulheres. É interessante perceber que tanto as músicas do funk ostentação, quanto as narrativas das alunas operam a partir de uma mesma matriz discursiva, pautadas por características como: a) os relacionamentos afetivo-sexuais realizam-se dentro da ordem heterossexual; b) é evidenciado, nas relações descritas, um protagonismo masculino como provedor material de figura feminina e esta, por sua vez, é destacada pelo provimento do sexo, servindo, também, como uma espécie de troféu a ser exibida.

Quando as alunas foram questionadas sobre Mc Pocachontas, ela foi descrita como exemplo de beleza e performance artística. Todas querem ser Mc Pocachontas! É interessante destacar que o fato de um homem financiar seus desejos e vontades, como a artista descreve na música, não é entendido como um problema para as alunas, mas como uma vantagem.

Amanda: Mc Pocachontas! Eu gosto muito!

Isabelly: Ah, eu amo ela! Ela não é bagaceira, e ela é linda!

Julia: Ela é linda! E eu gosto das músicas dela!

Evillyn: Ela é linda e as músicas dela são legais! Eu acho ela a Mc mais bonita que tem!

Pesquisadora: E por isso que tu gostas dela? Tu querias ser ela?

Evillyn: Ah, eu queria! Imagina "sora"! Tirar foto lá, naqueles carrões!

Nas narrativas das alunas, a beleza é apresentada como uma característica de suma importância para a organização de relacionamentos afetivo-sexuais. Ou seja, para as alunas o relacionamento não poderia estar baseado apenas nos recursos financeiros do seu parceiro, mas necessitaria 
atração física. Deste modo, a beleza parece constituir um valor que, junto com o consumo, também organiza posturas, opiniões e tangencia algumas das escolhas das alunas, como pode ser percebido nas narrativas abaixo:

Dora: Se for feio, como ele, eu não vou!

Eduarda: Dinheiro uma hora vai acabar e tu só vai ter aquele feio do teu lado! Pesquisadora: E beleza não acaba?

Eduarda: Mas daí, tu vais estar gostando ainda do cara e vai achar ele bonito! E tu também vai ficar velha...

Dora: Imagina! Ter que dormir com aquele cara feio do meu lado! Bem capaz!

No excerto acima, também é possível constatar que, apesar de algumas jovens acolherem a ideia de um homem provedor, outras esperam relacionamentos mais estáveis do que aqueles que aparecem nas músicas. Isto fica especialmente claro quando se referem ao fato de que a beleza irá acabar ao longo do processo de envelhecimento, mas elas ainda estarão em um relacionamento com o mesmo par, visto que ambos, na narrativa da aluna em destaque, "vão ficar mais velhos". Ou seja, suas percepções acerca dos relacionamentos mostram uma negociação de significados com as músicas, acolhendo parcialmente as representações que elas colocam em circulação. Cabe, então, questionar: estarão as jovens da atualidade, principalmente aquelas apreciadoras do estilo funk ostentação, organizando seus relacionamentos afetivo-sexuais sob este imperativo que articula beleza e consumo? As escolas têm discutido estas dimensões? E estariam aptas e abertas para isto?

\section{É PRECISO ESCUTAR MAIS!}

Frente às análises apresentadas, parece ser possível afirmar que as músicas alinhadas com o funk ostentação corroboram a ideia de Bauman (2005) de que, na contemporaneidade, o mundo configura-se como um palco de performances, no qual somos consumidores de bens de consumo, de bens culturais e até mesmo de relacionamentos. Como afirma o autor, as sociedades contemporâneas padecem da síndrome do consumo, na qual os desejos e os anseios pelos bens materiais devem ser atendidos de forma quase imediata, mesmo que os desejos não sejam atendidos pelas "versões originais" dos produtos apresentados pelas músicas de funk ostentação. Nas palavras do autor, tal síndrome envolve a "enfática negação da virtude da procrastinação e da possível vantagem de se retardar a satisfação [...] encurta 
radicalmente a expectativa de vida do desejo e a distância temporal entre este e a sua satisfação, assim como entre a satisfação e o depósito de lixo" (BAUMAN, 2008, p. 111).

Também ficou evidente que as jovens alunas adotam posturas orientadas por enunciados filiados a discursos que diferenciavam as possibilidades de homens e mulheres. As falas das alunas que participaram da pesquisa mostram sua adesão ao universo dos produtos de luxo. Assim, na esteira de Lazzarato (2006), é possível afirmar que elas consomem estes produtos, por manterem uma relação de pertença com o mundo em que estes produtos existem, mesmo que este consumo não se materialize em seus corpos. Porém, mais do que adesão a este universo, os dados produzidos pelas alunas mostram que seus ideais de relacionamento afetivo-sexual habitam estes mundos das quais elas participam como público. Elas sonham com a efetuação do consumo em seus corpos não por meio de renda própria, mas por meio de um parceiro que possa realizar estes sonhos.

Logo, para as jovens, as mulheres deveriam valer-se de sua sexualidade e de sua beleza para alcançar os benefícios materiais oferecidos pelos homens para o estabelecimento de uma relação. Autoras que problematizam a história das mulheres, tais como Del Priore (2009), Louro (1997), Meyer (2003), entre outras, mostram, através de seus estudos, que as práticas de sedução, submissão e dependência foram estimuladas, ao longo dos tempos, nas sociedades ocidentais, a fim de naturalizar alguns comportamentos como formas (in)adequadas do ser mulher e, consequentemente, do ser jovem mulher. Louro (2010), ao discorrer sobre o tema, pontua que a inscrição dos gêneros masculino ou feminino é sempre permeada pelas marcas de uma cultura. Logo, a forma de vivenciar a masculinidade e a feminilidade organiza-se a partir de padrões culturais, fato que permite compreender, em certa medida, porque as jovens pesquisadas, mesmo no século XXI, fomentam comportamentos de dependência financeira de seus parceiros e, ainda, pautam a escolha de seus relacionamentos afetivo-sexual em razão das benesses possíveis. Apesar dos avanços observados em relação à independência feminina, é preciso lembrar que "a histórica desigualdade nas relações entre homens e mulheres constitui profundamente não só o corpo feminino como também as identidades de gênero" (FISCHER, 2001, p. 592), como fica evidente nas análises aqui apresentadas.

Porém, ainda que o ideal de relacionamento esteja atravessado pela conquista do luxo, as jovens participantes também destacam a importância da beleza masculina, atributo que não parece ser levado em conta nas músicas 
analisadas. Mesmo considerando a necessidade de um parceiro que satisfaça seus sonhos de consumo, elas não parecem dispostas a abrir mão da atração física como elemento fundamental para suas relações. Também um tanto na contramão dos enunciados veiculados no funk ostentação, elas sinalizam desejar, em alguma medida, relacionamentos duradouros, revivendo um romantismo que parece ter sido abolido neste subgênero musical. Portanto, parece-nos possível afirmar que essas jovens acolhem parcialmente as representações veiculadas pelo funk ostentação, negociando esses significados de modo mais complexo do que a simples aceitação ou rejeição.

Além disso, é importante destacar que o estudo das produções culturais produzidas/consumidas nas periferias urbanas, a exemplo das músicas associadas ao subgênero funk ostentação, apresenta-se como um caminho profícuo para a análise das práticas sociais vividas pelos moradores que nelas habitam e também para compreensão dos discursos circulantes em tais espaços. Sobre o tema, também colaboram Helen Ferreira e Mauro José Costa (2010, p. 199):

A periferia não se situa mais como margem: tomou a produção de si mesma fazendo parte da cultura urbana; tem suas representações e cria visibilidade por meio de suas singularidades. Ela dita moda, faz arte, cria estilo, ameaça, incomoda, quebra barreiras, exige espaço, inventa uma cultura própria (local) [...]

Desta forma, entendemos como sendo profícuo o estudo e a problematização acerca das formas como os discursos colocados em circulação pelas músicas escutadas por alunas produzem modos de viver a feminilidade na atualidade, pois problematizar os modos de ser e de viver dessas jovens, nos tempos atuais, é possibilitar uma melhor compreensão das condições que organizam a constituição das culturas juvenis femininas. Apreender a constituição destas subjetividades, dos modos como estas alunas relacionam-se consigo mesmas, e como negociam significados e verdades, constitui-se em tarefa que contribui para produzir novas aproximações com estes sujeitos nos ambientes escolares em que circulam, tornando possível aprofundar a articulação entre suas experiências e o currículo. 


\section{YOUNG WOMEN FROM PERIPHERY AND THE OSTENTATION FUNK}

ABSTRACT: This article aims to analyze relations between young women studying in a school located on the periphery of the city of Porto Alegre (RS/Brazil) and the musical style ostentation funk. More specifically, it seeks to problematize the construction of ideals of affective-sexual relationships and gender relations by those young women in conjunction with such songs. Firstly, we analyze five songs with major evidence for those students and later we problematize data produced in discussion groups. Among the results we highlight the acceptance by those students to the statements that highlight men as financial promoters of women's dreams of consumption and their desire for longer-lasting relationships, opposing the representation of successive brief relationships presented in their favorite songs.

KeYwords: Cultural Studies. Genre. Consumption. Music.

\section{JÓVENES MUJERES DE PERIFERIA Y EL FUNK OSTENTACIÓN}

RESUMEN: Este artículo tiene como objeto analizar las relaciones establecidas entre jóvenes estudiantes de una escuela de periferia de la ciudad de Porto Alegre (RS) y el estilo musical "funk ostentação". De modo más específico, se busca problematizar la construcción de ideales de relaciones afectivo-sexuales y de relaciones de género, por las jóvenes en articulación con las referidas musicas. En primer lugar, se analizan las cinco músicas más populares entre las jóvenes y, posteriormente, problematizamos los datos producidos en los grupos de discusión. Entre los resultados, destacamos la aceptación de las jóvenes de los enunciados que destacan a los hombres como promotores financieros de los sueños de consumo femeninos y la aspiración de esas jóvenes por relaciones más duraderas, contrariando la representación de sucesivos relacionamientos breves presentados en sus canciones favoritas.

Palabras-clave: Estudios Culturales. Género. Consumo. Musica.

\section{NOTAS}

1) O morro não tem vez (Favela): composição de Antônio Carlos Jobim e Vinicius de Moraes (1963). A música também ficou conhecida pela interpretação de Elis Regina.

2) Da pobreza ao luxo: documentário produzido pelo programa Câmera Record. (2014). Disponível em: <http://noticias.r7.com/videos/da-pobreza-ao-luxo-camera-record-mostra-tudo-sobre-o-funk-ostentacao/idmedia/534f59100cf2671344e 5a516.html>. Acesso em: 08 ago. 2014. 
3) Caso o leitor deseje conhecer as músicas referidas, diversos sites apresentam vídeos e a transcrição da letra. Uma sugestão é o site Letras (https://www.letras.mus.br).

4) De acordo com Deleuze (1992), a sociedade atual se caracterizaria como uma sociedade de controle, que transforma os modos de ser e viver das modernas sociedades disciplinares. De acordo com Lazzarato (2006), as sociedades de controle se caracterizam por cérebros que se afectam à distância, por meio de dispositivos tecnológicos arrojados, ao que correspondem processos de subjetivação e sujeição para a formação de públicos.

5) A aluna refere-se ao órgão sexual feminino.

\section{REFERÊNCIAS}

BAUMAN, Z. Vidas Desperdiçadas. Rio de Janeiro: Jorge Zahar, 2005.

Vida para consumo: a transformação das pessoas em mercadorias. RJ: Jorge Zahar, 2008.

CABRAL, S. Surgem as escolas de samba. In: As escolas de samba do Rio de Janeiro. Rio de Janeiro: Lumiar, 1996. p. 59-93.

COELHO, F. Espaço urbano e música popular no Rio de Janeiro. Acervo, Rio de Janeiro, v. 17, n. 1, p. 81-98, jan./jun. 2004.

COSTA, M. V. Sobre as contribuições das análises culturais para a formação dos professores do início do século XXI. Educar, Curitiba, n. 37, p. 129-152, maio/ago. 2010.

DAYRELL, J. A música entra em cena: o rap e o funk na socialização da juventude em Belo Horizonte. 2001. 409 f. Tese (Doutorado em Educação). Programa de Pós-Graduação em Educação, Faculdade de Educação da Universidade de São Paulo, São Paulo, SP, 2001.

. O rap e o funk na socialização da juventude. Educação e Pesquisa, São Paulo, v.28, n. 1, p. 117-136, jan./jun. 2002.

DELEUZE, G. Conversações. Rio de Janeiro: 34, 1992.

DEL PRIORE, M. História das mulheres no Brasil. 9.ed. São Paulo: Contexto, 2009.

FERREIRA, H. P.; COSTA, M. J. R. Do local ao global: o serviço de radiodifusão comunitária e sua inserção no ciberespaço. In: SOBREIRA, H. G. (Org.). Educação, culturas e comunicação nas periferias urbanas. Rio de Janeiro: Lamparina, 2010. p. 197-210.

FISCHER, R.M. Mídia e educação da mulher: sobre modos de enunciar o feminino na TV. Revista Estudos Feministas, Florianópolis, v. 9, n. 2, p. 586-599. 2001.

HERSCHMANN, M. O funk e o hip hop invadem a cena. Rio de Janeiro: Ed. UFRJ, 2005.

LAZZARATO, M. As revoluções do capitalismo. Rio de Janeiro: Civilização Brasileira, 2006. 
LIMA, L.F.N. O pagode dos anos 80 e 90: centralidade e ambivalência na significação musical. Revista Em Pauta, v. 13, n. 12, p. 89-111, 2002.

LOURO, G. L. Gênero, sexualidade e educação: uma perspectiva pós-estruturalista. Petrópolis: Vozes, 1997.

Pedagogias da Sexualidade. 3 ed. In: LOURO, Guacira Lopes (Org). O corpo educado: pedagogias da sexualidade. Belo Horizonte: Autêntica, 2010. p. 07-34.

MEINERZ, C.B. Grupos de Discussão: uma opção metodológica na pesquisa em educação. Educação \& Realidade, v. 36, n.2, p. 485-504, maio/ago., 2011.

MEYER, D. E. Gênero e educação: teoria e política. In: LOURO, G.; NECKEL, J. F.; GOELLNER, S. V. (Org.). Corpo, gênero e sexualidade: um debate contemporâneo na educação. Petrópolis: Vozes, 2003. p. 9-27.

PLATT, D; NEATE, P. Cultura é nossa arma: AfroReggae nas favelas do Rio. Rio de Janeiro: Civilização Brasileira, 2008.

SARAIVA, K.; VEIGA-NETO, A. Modernidade líquida, capitalismo cognitivo e educação contemporânea. Educação \& Realidade, Porto Alegre, v. 34, n. 2, p.187-201, maio/ ago. 2009.

VIANNA, H. O mundo funk carioca. Rio de Janeiro. Jorge Zahar, 1987.

Karla Saraiva: Doutora em Educação pela Universidade Federal do Rio Grande do Sul (UFRGS), professora do Curso de Pós-Graduação em Educação da Universidade Luterana do Brasil (ULBRA).

E-mail: karlasaraiva@via-rs.net

JuLIANA VARGAS: Doutora em Educação pela Universidade Federal do Rio Grande do Sul (UFRGS). Professora do Programa de Pós-Graduação em Educação da Universidade Luterana do Brasil (ULBRA). E-mail: julivargas10@hotmail.com 